M. Di Domenico, P. Gerlinger, M. Aigner

"Development and validation of a new soot formation model for gas turbine combustor simulations"

Combustion and Flame, vol. 157, num 2, pages 246 - 258, 2010

The original publication is available at www.elsevier.com

DOI: 10.1016/j.combustflame.2009.10.015 
Development and validation of a new soot formation model for gas turbine combustor simulations

\author{
Authors: \\ Di Domenico, M., Gerlinger, P., Aigner, M. \\ DLR - German Aerospace Centre, \\ Institute of Combustion Technology
}

Contact Information:

Massimiliano Di Domenico

Pfaffenwaldring 38-40

70569 Stuttgart

Germany

Tel.: +497116862363

Fax.: +497116862578

massimiliano.didomenico@dlr.de

full-length article 


\title{
Development and validation of a new soot formation model for gas turbine combustor simulations
}

\author{
Di Domenico, Massimiliano,b, Gerlinger, Peter $^{\mathrm{b}}$, Aigner, Manfred ${ }^{\mathrm{b}}$ \\ ${ }^{a}$ DLR - German Aerospace Centre, Pfaffenwaldring, 38-40, 70659 Stuttgart, Germany
}

\begin{abstract}
In this paper a new soot formation model for gas turbine combustor simulations is presented. A sectional approach for the description of Polycyclic Aromatic Hydrocarbons (PAHs) and a two-equation model for soot particle dynamics are introduced. By including the PAH chemistry the formulation becomes more general in that the soot formation is neither directly linked to the fuel nor to $\mathrm{C}_{2}$-like species, as it is the case in simpler soot models currently available for CFD applications. At the same time, the sectional approach for the PAHs keeps the required computational resources low if compared to models based on a detailed description of the PAH kinetics. These features of the new model allow an accurate yet affordable calculation of soot in complex gas turbine combustion chambers. A careful model validation will be presented for diffusion and partially premixed flames. Fuels ranging from methane to kerosene are investigated. Thus, flames with different sooting characteristics are covered. An excellent agreement with experimental data is achieved for all configurations investigated. A fundamental feature of the new model is that with a single set of constants it is able to accurately describe the soot dynamics of different fuels at different operating conditions.
\end{abstract}

Key words: soot formation, PAH sectional approach, finite-rate chemistry,

\footnotetext{
${ }^{*}$ Corresponding author

Email address: Massimiliano.Didomenico@dlr.de (Di Domenico, Massimiliano)
} 
diffusion flames, partially premixed flames 


\title{
Development and validation of a new soot formation model for gas turbine combustor simulations
}

\author{
Di Domenico, Massimiliano,,b ${ }^{*}$ Gerlinger, Peter $^{\mathrm{b}}$, Aigner, Manfred ${ }^{\mathrm{b}}$ \\ ${ }^{b}$ DLR - German Aerospace Centre, Pfaffenwaldring, 38-40, 70659 Stuttgart, Germany
}

\section{Introduction}

In gas turbine combustion chambers soot particles are unwanted products, as they decrease the combustion efficiency and increase the wall heat load [1]. Accurate numerical simulations of soot formation become of increasing importance as more stringent emission rules are issued and new combustion chamber geometries are needed to fulfil them [2]. However, the design of low-emission combustors is far from being simple due to their complex flow structures with large variations of the local premixing ratio, temperature, and gas composition.

One of the most demanding problems in soot modelling is the complexity of the formation process, which even today is still under investigation. It is well accepted that soot results from thousands of reactions involving hundreds of species (soot precursors). It has also been proved that empirical relations are not able to describe the whole process properly. Even for simple ethylene flames, Mauss et al. [3] could not find a direct dependence of the soot formation rate on the fuel partial pressure. Only the HACA (hydrogen abstraction, carbon addition) [4] mechanism was able to reproduce the experimental data. In another publication [5], Appel and coworkers demonstrated that species like methane

\footnotetext{
${ }^{*}$ Corresponding author

Email address: Massimiliano.Didomenico@dlr.de (Di Domenico, Massimiliano)
} 
(which does not belong to the soot precursor species) may affect soot nucleation, growth and oxidation rates. Thus, it may be concluded that a coupling of the gas phase reactions with the soot formation model is needed.

Detailed formulations using elementary reactions for the gas phase and soot can be found in e.g. in Refs. $[6,7,8]$. These approaches represent the most rigorous way of handling the soot formation, and allow accurate predictions even in flames running under high pressure conditions [9]. As these simulations deliver comprehensive datasets, they may also give insight in the soot formation dynamics, e.g. the key role of benzene [10] or the importance of the PAH coagulation step [5] on the soot formation rate and on the soot particle number distribution [11].

The main disadvantage of such detailed models is that they may not be applied to real configurations (i.e. gas turbine combustion chambers), as their complexity would make the simulation of three-dimensional geometries unfeasible. However, they may be used in combustion models which separate flow and chemistry timescales (i.e. flamelet approaches). On the other hand, such numerical simulations would suffer from limited ranges of applicability caused by the hypotheses underlying the combustion model.

For these reasons, less complex approaches of soot modelling are needed for practical applications. Direct correlations between the soot formation rate and the mixture fraction [12] belong to the most simple solutions but are limited to cases where a definition of a mixture fraction space is possible. More general formulations can be achieved if reduced chemical mechanisms are employed [13]. In this case the soot formation rate may be linked to species like acetylene. However, even such approaches are far from being general, as they neglect all intermediate steps of $\mathrm{PAH}$ formation and growth.

An attempt to include PAH chemistry into a soot formation model for CFD 
calculations was presented by Zamuner and Dupoirieux [14]. However, no general framework to accommodate an arbitrary number of PAH classes was developed, and a linear distribution for PAH concentrations was assumed. This simplifies the model but also reduces its generality significantly, since the PAH classes are not independent and unphysical constrains are applied. Moreover, Zamuner and Dupoirieux only investigated ethylene combustion.

It may be concluded that there still is a lack in affordable but accurate models to simulate soot in gas turbine combustors. A simplification of the gas phase and soot precursor chemistry is not trivial, as in many cases dropped species and reactions reduce the range of validity of the model. An important guideline is that a soot model should include all important physical steps like fuel break-up, formation of fuel radicals, smaller olefins and unsaturated fragments, $\mathrm{PAH}$ inception and recombination into combustion products, and finally soot nucleation [15]. Even if the importance of the different steps may vary according to the fuel or fuel blend used, none of them should be omitted.

Another fundamental aspect is a careful validation of the different parts of the soot model. Of special interest are laminar diffusion flames [16, 17], since no turbulence modelling is required. Most of the studies in literature are focused on small hydrocarbons (methane [18, 19], ethylene [20]) whereas only few works deal with more realistic fuels used in aero-engines (kerosene or kerosene surrogates [21]). In this context partially premixed flames are of particular interest, where different combustion regimes coexist and contribute to heat release and soot formation. Experimental works on partially premixed flames are available in literature $[22,23]$ and cover measurements of main species, soot precursors and soot particles. Numerical simulations of such configurations have been performed e.g. by Smooke et al. [23], but in this work soot formation was not included. 
The soot model which will be presented in this paper is able to fill the gap between the accurate but expensive detailed formulations and the simple but less accurate engineering approaches. It includes all important aspects outlined above in a manner which allows its implementation in general-purpose CFD codes. It should be pointed out that no additional hypothesis on the soot formation paths are done, and that the main aim of this work is to present a soot precursor and soot particle model based on the current knowledge of the chemical processes presented above. PAH chemistry is included to ensure model generality and a sectional approach is adopted to describe the PAH distribution. In order to enable the simulation of different flame regimes, a detailed finite-rate chemistry combustion model is used. A careful validation including diffusion and partially premixed flames will be given. It will be shown that after the determination of the model constants using a methane diffusion flame, no further model adjustments are required in order to obtain excellent predictions even for ethylene and kerosene flames.

\section{Model formulation}

In order to illustrate the new soot formation model, a sketch of its basic components is shown in Fig. 1. The model has a block structure and the finiterate chemistry submodel may be used with or without the PAH classes and the soot particle equations. In Fig. 2 an example of the sectional approach for the PAHs is given (here for four PAH classes). The PAH concentrations (in ppm) are given for each PAH class at the base and the tip of the flame presented in Sec. 3. While the distribution is monotonic at the flame base, a minimum for the third PAH class is obtained at the flame tip. 


\subsection{Combustion chemistry}

The reaction mechanism is responsible to accurately describe fuel break-up, formation of small molecules and radicals, as well as recombination into final combustion products. In order to retain as many details of the combustion process as possible, elementary reactions are used, and no lumping procedure is applied. A fundamental aspect is the choice of the upper mass limit for species included in the kinetic scheme. A comprehensive scheme would include all species up to the incipient soot particle, but this would increase the computational time beyond any affordable limit. On the other hand, a limitation of the kinetic scheme to the $\mathrm{C}_{1}$ and $\mathrm{C}_{2}$ kinetics would significantly reduce the range of applicability of the model. A compromise is that only species and related paths up to benzene $\left(\mathrm{C}_{6} \mathrm{H}_{6}\right)$ are modelled by elementary reactions. As benzene has been found to be a rate-limiting species in soot formation [10], this assumption has a strong physical basis. Moreover, our choice represents an improvement in comparison to most soot models in use [24], which limit the elementary chemistry to significantly smaller species $\left(\mathrm{C}_{2} \mathrm{H}_{2}\right)$.

Transport equations for enthalpy and species mass fractions are solved in a coupled implicit fashion to allow a stable integration even in case of stiff sets of numerical equations. An analytical form of the Jacobian matrix of the chemical source terms is used. This approach avoids discretization errors which are associated with a numerical evaluation of the derivatives.

A crucial point is the choice of a suitable kinetic mechanism, since it affects both combustion and soot formation. According to the flame investigated, different kinetic mechanisms are employed; a complete list with references is given in Table 1. The mechanism of Appel et al. [4] has been developed for soot formation modelling. In comparison to the original version where species up to pyrene $\left(\mathrm{C}_{16} \mathrm{H}_{10}\right)$ are included, the mechanism is reduced in this work by discard- 
ing reactions of species heavier than benzene. As the mechanism is employed for $\mathrm{C}_{2}$ flames only, this change is not expected to have a significant impact on the numerical results.

The mechanism proposed by Bittker [25] has the advantage to include benzene and related kinetic paths while at the same time keeping the number of species relatively small. The benzene formation paths B1 and B2 proposed by D'Anna and Kent [26] are added, since the original mechanism was developed to describe benzene decomposition only. The B1 path models the combination of C3 radicals $\left(\mathrm{H}_{2} \mathrm{CCCH}\right)$ whereas the addition of acetylene to $n-\mathrm{C}_{4} \mathrm{H}_{5}$ is included in the B2 path. An additional benzene formation path (B3) presented in the original work has not been included, as its contribution to benzene formation in methane flame was negligible. Moreover, as suggested in the work of Knystautas et al. [27], $\mathrm{C}_{4} \mathrm{H}_{4}$ is removed since it causes numerical instabilities while only marginally affecting the results.

The last scheme used in this paper has been developed to model kerosene combustion in gas turbine applications [28], and is a reduced mechanism for CFD applications. The validation was performed at pressures ranging from 1 to $60 \mathrm{~atm}$ and stoichiometric ratios ranging from one to two. A distinctive feature of this mechanism is a high accuracy in the prediction of aromatic species, which is an important aspect for the soot precursor submodel, as it will explained in the next section.

\subsection{PAH chemistry}

Soot precursors and in particular PAH molecules play an important role in the soot nucleation process, as they are responsible for transferring mass (in particular carbon atoms) from small fuel fragments to incipient soot particles. In order to take PAHs and related reactions into account, a sectional approach is a general yet computationally affordable method. The mass interval between 
the heaviest elementary species included in combustion chemistry (benzene in this work) and the lightest soot particle is filled with PAH classes. For each class a transport equation and irreversible reactions are defined. The chosen approach offers two advantages:

1. the number of additional transport equations required to describe the PAH chemistry is small. Indeed, it is possible to cover the whole interval by only a few (i.e. four classes), but retain the chemical dynamics of the soot precursors, as for each class different reactions can be defined.

2. the number of PAHs can be changed easily according to the testcase under consideration or the resolution needed for the description of the PAH distribution.

In this paper all PAHs are defined to be in the mass range from 100 to 900 amu. In order to investigate the impact of the number of PAH classes on soot, simulations of the methane flame have been performed with four and eight PAH classes, respectively. The modelling of the PAH source terms follows the current knowledge of the processes involved and include formation, growth and oxidation $[29,30,31,32]$. As the PAH classes are built according to a mass criterium and no hypothesis are made on the reactivity of the species included in each class, the method presented in this paper is quite different from a chemical lumping approach, like that of Frenklach in Ref. [33].

The formation of the first PAH is given by the reaction of benzene and acetylene

$$
\mathrm{C}_{6} \mathrm{H}_{6}+\mathrm{C}_{2} \mathrm{H}_{2} \rightarrow \mathrm{PAH}_{1},
$$

which is consistent with the HACA mechanism [4], as benzene can be considered to be the lightest PAH. Because Eq. (1) is a simplification of the actual steps 
involved [4], the corresponding reaction rate

$$
R R_{(1)}=k_{f}^{p f o r}\left[\mathrm{C}_{6} \mathrm{H}_{6}\right]\left[\mathrm{C}_{2} \mathrm{H}_{2}\right][R M]
$$

requires a reaction marker $(R M)$, which assures that PAHs are formed in the most reactive zones of the flame only. The use of $\mathrm{H}$ and $\mathrm{CH}$ as reaction marker has been investigated [34]. The observed differences in soot formation are small and neither the shape of soot distribution nor the sooting characteristics of the flame have been affected significantly.

The PAH growth is modelled by the sum of two contributions:

- the addition of acetylene

$$
\mathrm{PAH}_{k}+\mathrm{C}_{2} \mathrm{H}_{2} \rightarrow \mathrm{PAH}_{k+1},
$$

with the reaction rate

$$
R R_{(3)}=k_{f}^{p g w t h}\left[\mathrm{C}_{2} \mathrm{H}_{2}\right]\left[\mathrm{PAH}_{i}\right]\left(\frac{\Delta M}{M_{w_{k+1}}-M_{w_{k}}}\right)
$$

which is calculated with the fraction of the PAH interval which is affected by the $\mathrm{C}_{2} \mathrm{H}_{2}$ addition. That is

$$
\Delta M=\frac{M_{w_{k+1}}-M_{w_{k}}}{n_{s}} .
$$

$n_{s}$ is the number of subintervals into which the PAH class is divided.

- and the PAH-PAH interaction

$$
\mathrm{PAH}_{i}+\mathrm{PAH}_{j} \rightarrow \mathrm{PAH}_{k}
$$


with the reaction rate

$$
R R_{(6)}=\gamma_{i j} \beta_{i j} N_{a v}\left[\mathrm{PAH}_{i}\right]\left[\mathrm{PAH}_{j}\right]
$$

which includes the collision frequency $\beta_{i j}$ [35] (based on the averaged PAH mass) and the collision efficiency $\gamma_{i j}$ (set to $0.3[30]$ ). $N_{a v}$ is the Avogadro number.

A global step is also used for PAH oxidation

$$
\mathrm{PAH}_{k}+O X \rightarrow \mathrm{PAH}_{k-1}+O X P
$$

where $O X$ is an oxidiser (i.e. $\mathrm{O}_{2}$ or $\mathrm{OH}$ ) and $O X P$ represents an oxidation product. Similarly to Eq. (4), the calculation of

$$
R R_{(8)}=k_{f}^{p o x}[O X P]\left[\mathrm{PAH}_{i}\right]\left(\frac{\Delta M}{M_{w_{k}}-M_{w_{k-1}}}\right)
$$

includes only a fraction of the $\mathrm{PAH}_{i}$ concentration (expressed by the last term in Eq. (9)).

The rate constants of the PAH reactions are calculated by Arrhenius-like functions; all required parameters are listed in the first part of Table 3. Their determination is the result of a careful analysis of data available in literature. As our lumped formulation of PAH kinetics does not have many counterparts in literature, analogies based on the physical processes have been exploited. Both Eqs. (1) and (3) are expressions derived from the HACA mechanism (except for the use of $R M$ in Eq. (1)), thus they are modelled with the corresponding set of constants. In our simulations they are derived from the work of SkjøtRasmussen et al. [31], where a detailed reaction mechanism for elementary $\mathrm{PAH}$ species is presented. In that work all growth reactions involving radical 
PAHs (A3-A4) and acetylene contain the same set of Arrhenius parameters. They are used in this work without any further modification. The oxidation parameters are taken from Kazakov et al. [9] with the exception that in this paper reverse reactions are neglected. The sectional approach does not indeed allow the definition of the thermodynamical properties necessary to estimate the reverse Arrhenius constants: the mass interval which defines each PAH may cover actual PAHs having completely different structures and therefore different thermodynamical properties. The determination of reverse reaction constants would require a long theoretical treatment which would be out of the scope of this paper. Additionally, the reaction constants could not be validated due to the lack in experimental data.

As stated before, each PAH class is formed or destructed by one or more source terms as defined by Eqs. (1)-(8). Table 2 summarises these processes. In this work PAH growth and oxidation may take place for any PAH class, whereas PAH formation is possible the lightest PAH class only. Additionally, the final soot formation step (presented in the next section) can take place in each class if the limits of PAH masses and the minimum soot mass are fulfilled.

\subsection{Soot particle equations}

The soot particle distribution is described by a two-equation model for the soot mass fraction $Y_{s}$ and soot particle number density $n_{s}$. It follows that a mono-disperse distribution is obtained, where the particle diameter

$$
d_{s}=\sqrt[3]{\frac{6}{\pi} \frac{\rho Y_{s}}{\rho_{s} n_{s}}}
$$

and the specific particle area

$$
A_{s}=\left[36 \pi n_{s}\left(\frac{\rho Y_{s}}{\rho_{s}}\right)^{2}\right]^{\frac{1}{3}}
$$


are derived from the implemented soot variables.

The formation of the smallest particles is modelled by the collision of PAHs with masses which add up to a value higher than a predefined minimum soot mass. This is described by the global step

$$
\mathrm{PAH}_{i}+\mathrm{PAH}_{j} \rightarrow \mathrm{C}_{s}
$$

and the corresponding reaction rate is evaluated according to Eq. (7).

The addition of acetylene

$$
\mathrm{C}_{2} \mathrm{H}_{2}+\mathrm{C}_{s} \rightarrow \mathrm{C}_{s}
$$

and PAHs

$$
\mathrm{PAH}_{i}+\mathrm{C}_{s} \rightarrow \mathrm{C}_{s}
$$

to soot particles contributes to the growth process. The reaction rate of Eq. (13)

$$
R R_{(13)}=k_{f}^{s g w t h}\left[\mathrm{C}_{2} \mathrm{H}_{2}\right] A_{s}
$$

uses the specific soot particle area $A_{s}$ (obtained from Eq. (11)). As two-equation models for soot particles are quite common in literature [36, 37, 38], the Arrhenius constants for the acetylene condensation can be taken from any of these references. In this paper the constants derived by Lindstedt [13] are used. The rate constants for the condensation of PAHs on the soot surface (Eq. (14)) is given by

$$
R R_{(14)}=\gamma_{k s} \beta_{k s}\left[\mathrm{PAH}_{k}\right] n_{s}
$$

and has an expression similar to the PAH-PAH collision model (Eq. (7)). However, in this case the collision frequency is based on the average soot particle diameter [39]. The collision efficiency $\gamma_{i s}$ is taken to be 0.3. 
Soot oxidation is modelled according to the one-step irreversible reaction

$$
\mathrm{C}_{s}+O X \rightarrow \mathrm{C}_{s}+O X P \text {. }
$$

$\mathrm{OH}$ and oxygen are considered as oxidisers, and the reaction rate

$$
R R_{(17)}=\eta_{i} k_{f_{i}}^{s o x}\left[O X_{i}\right] A_{s}
$$

introduces an oxidation efficiency, as suggested by Wen et al. [38].

The last contribution considered in the model is agglomeration among soot nuclei

$$
R R_{a g g}=-k_{a g g} n_{s}^{\frac{11}{6}} A_{s}
$$

which reduces the number of soot particles but does not alter the total soot mass. An agglomeration constant of 3 is used [13]. The Arrhenius parameters for the described soot reactions are summarised in the second part of Table 3 .

Beside chemical processes and convective transport, thermophoresis is included in the soot particle transport equations as it may affect the soot distribution, especially at low flow velocities and in regions with high temperature gradients. The well accepted formulation from Santoro et al. [40]

$$
\mathbf{v}_{t h}=-C_{t h} \nu \frac{\nabla T}{T},
$$

is used with $C_{t h}=0.55$.

In heavily sooting flames with soot volume fraction above one ppm (see subsections 3.2 and 3.3) the impact of soot radiation on the enthalpy equation should be considered. In this work a simple volumetric radiation source term

$$
q_{R}=C_{R} f_{v} T^{5} .
$$


which neglects self-absorption and gas phase radiation is included. A good agreement between numerical and experimental profiles in ethylene diffusion flames [41] could be obtained using Eq. (21) and $C_{R}=10^{-4}$.

\subsection{DLR THETA code}

All simulations presented in this paper are performed with the in-house DLR THETA-code. The fluid, species, PAH and soot transport equations are solved on a vertex-centred unstructured grid. An incompressible version of the SIMPLE method [42] is used for pressure-velocity coupling. Second-order upwind and central schemes are employed for the discretization of convective and diffusive fluxes, respectively. A bi-conjugate gradient stabilised solver with diagonal preconditioning for the linearised equations and a geometrical multigrid for the pressure correction equation are used.

\section{Results and discussion}

\subsection{Methane/air diffusion flame}

The atmospheric, laminar, methane-air, diffusion flame of Smooke and coworkers [43] is the first benchmark for the new soot formation model presented. This testcases is also used to validate the model constants.

The geometrical configuration of the experimental setup may be found in the original paper [43] and therefore is only briefly outlined here. An inner, 12 $\mathrm{mm}$ vertical brass tube issues a methane jet surrounded by an oxidiser (air). An over-ventilated sooting flame is obtained. Smooke et al. [43] published soot, temperature and species data as well as results of their numerical simulations, which later will be used for comparison.

Numerical simulations are performed for an axysimmetric 5-degrees wedge which is discretized by 150 and 90 volumes (mainly hexahedral) in the axial 
and radial direction, respectively. Elements are clustered in regions where mixing and combustion take place, so that high spatial gradients can be resolved properly. Moreover, it has been taken care that there is a smooth transition to larger cells placed in the outer regions. Unless otherwise stated, the kinetic scheme of Appel, Bockhorn and Frenklach [4] (which is referred as ABF) and four classes for the PAH submodel are used. Buoyancy effects are considered, as low inlet velocities and high temperatures in the combustion zone promote an axial acceleration of the hot fluid.

The boundary conditions for this test case are summarised in Table 4. At the outlet and at the symmetry axis zero gradients for all quantities are assumed. Bulk fuel inlet velocities are given in the table, while corresponding fully developed laminar profiles are used in the computation. As observed by Smooke et al. [43] and confirmed in Refs. [44, 45], the simulated flame shape, temperature and soot distribution are strongly affected by burner preheating effects. This is taken in the presented simulations into account by increasing the inlet temperature for both fuel and air (420 K instead of $300 \mathrm{~K}$ ) as proposed in Ref. [43].

\subsubsection{Temperature and species profiles}

In order to asses the overall accuracy of the combustion model, a comparison with experimental data is performed. Radial profiles of temperature, acetylene and benzene at heights 1.0, 1.5, 2.0 and $2.5 \mathrm{~cm}$ above the burner are compared with data obtained from simulations with (using both the ABF and the Bittker mechanisms) and without the soot model (ABF mechanism only). The temperature profiles are given in Fig. 3. The agreement between experiment and simulation is very good, in particular if uncertainties concerning the inlet boundary conditions (i.e. preheating effects) are considered. Especially the peak temperatures agree very well and demonstrate that gas radiation (not included) 
is not significant. At $x=1.0 \mathrm{~cm}$ and $x=1.5 \mathrm{~cm}$ the temperature at the axis is slightly underpredicted. This is probably due to burner preheating effects and/or to a poor description of the fuel-rich chemistry. Similar discrepancies are also observed in Ref. [43], where the GRI 2.11 mechanism is adopted. At the outer side of the flame both temperature and flame thickness are overestimated. As grid convergence has been checked [34], the actual burner geometry (i.e. burner lip) or incorrect coflow profiles may be possible explanations for these deviations. However, there is also a visible influence of the kinetic mechanism on the outer part of the temperature profiles. Here the ABF mechanism achieves a better agreement with the experiments than the Bittker mechanism.

Next, acetylene and benzene profiles (plotted in Figs. 4 and 5) are discussed. In these plots differences resulting from the kinetic schemes become more evident and the influence of the number of PAH classes is investigated. Both acetylene and benzene molar fractions drop if the soot model is activated. This demonstrates that the interaction between soot and chemistry cannot be neglected. Strong differences between the Bittker and the ABF mechanism are observed. Because acetylene and benzene are key species for the soot formation, the soot profiles (see Fig. (6)) show similar differences between both mechanisms. On the other hand, a limited impact of the number of PAH classes on benzene and acetylene is observed, as a doubling of the number of PAH classes causes a small shift between both profiles only.

Even if there are some discrepancies in the acetylene and benzene profiles, the overall agreement between experimental and numerical data is very good. Best predictions are obtained in the hottest parts of the flame, where the experimental and computed acetylene concentrations almost match. The largest discrepancies are found at the axis, where the acetylene concentration is underpredicted. Similar considerations hold for the benzene profiles, where the errors 
at $r=0$ are even slightly higher. While the experimental benzene profiles have a monotone behaviour, the computed profiles show a peak at the location of maximum temperature. However, as soot is mainly produced in hot regions the agreement of these profiles is more than satisfactory with respect to soot model validation.

\subsubsection{Soot volume fraction profiles}

Simulated soot volume fraction profiles are compared against measurements in Fig. 6. Concerning the experimental method used in [43] and presented in [46] it has been demonstrated that it is able to measure both dark and translucent soot particles and that its measurements can be directly compared to the numerical predictions given by a soot formation model, as done by Smooke and coworkers [43]. In the plots presented in Fig 6 the differences between the ABF and the Bittker mechanisms are still more evident and point out the coupling between the gas phase chemistry and soot. A strong correlation between benzene and soot is observed, i.e. simulations with high benzene molar fractions also show high soot volume fractions. The comparison with the experimental data demonstrates that the model is able to predict trends, maximum values and their position well. While the influence of the number of PAH classes on the ethylene and benzene profiles was relatively small, the differences increase in case of soot volume fractions. If $8 \mathrm{PAH}$ classes are used, the peak values are approximately $20 \%$ higher compared to simulations using four PAH classes. Nevertheless, the differences are relatively small especially if experimental uncertainties are taken into account. Thus, the following testcases will use four PAH classes only.

The soot model is able to predict the location of the soot maximum for heights lower than $2.25 \mathrm{~cm}$ with the $\mathrm{ABF}$ mechanism very well. Above this height the experimental peak values move faster towards the axis than in the 
simulation. On the other hand using the Bittker mechanism the peak locations are shifted further away from the axis, while the peak values are better reproduced. A shift of the soot peak values is also obtained in the simulations of Smooke et al. [43] (shown in Fig. 6), where it already appears at lower heights above the burner. Compared to the soot simulations of Smooke et al. a considerable improvement in soot prediction is achieved by the new model. As the main difference between both formulations is the introduction of the PAH chemistry it may be concluded, that this feature is responsible for the improvements observed. It is worth to point out that the model presented in Ref. [43] introduces a sectional approach for the soot particles while in our work the attention is focused on the soot precursors. Additionally, in Ref. [43] two particular PAH species $\left(\mathrm{C}_{10} \mathrm{H}_{7}\right.$ and $\left.\mathrm{C}_{14} \mathrm{H}_{10}\right)$ are considered as direct contributors of the soot inception step. As our PAH section approach is designed to cover significantly larger molecular mass ranges (100-900 amu) further comparisons between the two approaches are not possible.

\subsubsection{PAH and soot distributions}

Two-dimensional flow and temperature plots for the flame of Smooke et al. [43] may be found in Refs. [47, 43] and are not repeated in this paper. Instead, we focus on the PAH and soot fields, because they give insight in how the soot model works. In order to show the flame position the $T=1300 \mathrm{~K}$ isoline is given.

In Fig. 7 distributions of the different PAH classes are plotted. The production of the first PAH is directly related to benzene and acetylene, e.g. high concentrations of $\mathrm{PAH}_{1}$ are found in regions of high $\mathrm{C}_{6} \mathrm{H}_{6}$ and $\mathrm{C}_{2} \mathrm{H}_{2}$ concentrations. By using several PAH classes the model introduces further degrees of freedom and considers convective and diffusive transport of the PAHs. A significant variation of both shape and peak locations of the distributions from 
$\mathrm{PAH}_{1}$ to $\mathrm{PAH}_{4}$ is observed. It is associated with the residence time of each PAH class and with the competing process of conversion into soot. The physical behaviour that soot is not directly formed from small radicals is accounted for by solving PAH transport equations. This represents an advantage of the new model, which is able to follow the whole spatial (temporal) path from gaseous species to soot. It should be noticed that although the model is able to give a physically reasonable description of PAH dynamics, the simplification implied in the sectional approach and the lack of information on the PAH structure do not allow a parallel with experimentally detected high mass molecular structures (e.g. nanoparticles of organic carbon [48]).

The distributions of soot volume fraction and soot number density are plotted in Fig. 8. As expected, the soot particle number distribution $N_{s}$ is strongly correlated to the $\mathrm{PAH}_{4}$ field. In both cases two distinct peaks can be identified at corresponding positions. The soot volume fraction distribution instead has a single peak which is located in the fuel rich region. From the position of the lower $N_{s}$ peak and the $f_{v}$ peak it becomes clear that young soot particles are first formed near the flame base. Their size is extremely small and despite the large number of soot nuclei the soot volume fraction is negligible. Moving downstream the particle number density decreases and soot volume fraction increases by agglomeration and growth processes, respectively. It is also observed that the particle number density at the location of the $f_{v}$ maximum is relatively low. There is also a second $N_{s}$ peak located along the axis at $h=2.5 \mathrm{~cm}$, which does not result in a second maximum for the soot volume fraction. This is due to the low acetylene concentrations found in this region and the proximity of the stoichiometric line [34], which limits the region where PAH may exist and form soot. It is also important to notice that both PAHs and soot are found in regions with temperatures higher than $1300 \mathrm{~K}$, meaning that no unphysical 
low-temperature soot formation takes place. This a good result, considering that the sectional approach does not explicitly include any transport equation for the $\mathrm{PAH}$ radicals.

From the above investigations it can be concluded that soot formation is a very dynamic process which starts from the acetylene and benzene chemistry but evolves according to the PAH kinetics. Both chemical and transport phenomena affect the soot dynamics and it has been shown that the new soot model is able to accurately describe all relevant processes.

\subsection{Partially-premixed ethylene flame}

The atmospheric, laminar, partially-premixed ethylene flame of McEnally and coworkers [22] is the next testcase under consideration. The geometrical setup is similar to the methane flame investigated before: a partially-premixed fuel stream is surrounded by a coflow which is confined by an external housing. The only difference is a ring placed above the air inlet, which partially reduces the inlet area, increases the inlet velocities and stabilises the flame [22]. Experimental measurements include temperature, main non-fuel species (i.e. methane, acetylene, benzene) and soot profiles along the axis. In the original work [22], data are available for several degrees of premixing $(\phi=\infty, 24,12,6,4,3)$. In this paper for the sake of brevity we present results of the $\phi=6$ case only, although the soot model has been tested for all mentioned premixing ratios [34]. The $\phi=6$ case is a good compromise between a high degree of premixing and a flame structure still dominated by the diffusion between the air and fuel streams.

There are few works concerned with the simulation of partially premixed flames. As example, Bennet et al. [23] and Claramunt et al. [49] simulated such flames and investigated the inner structure of the reaction region, but in none of these works soot formation was included. On the other hand, soot models 
are validated either for perfectly premixed $[11,50]$ or diffusion flames $[51,52]$, but not for both regimes simultaneously. For these reasons this work represents a first attempt to provide a comprehensive validation of the new soot formation model.

The numerical boundary conditions for the McEnally et al. testcase are summarised in Table 5. Again, bulk values are given for the inlet velocities while fully-developed laminar profiles are used in the simulation. Compared to the methane testcase, an ambient inlet temperature is adopted. The computational grid consists of 180 and 105 elements in the axial and radial directions, respectively. All soot model parameters are kept constant and no further adjustment is performed.

\subsubsection{Temperature, species and soot profiles}

Comparison of the experimental data and numerical predictions are performed for simulations with and without soot radiation (see Eq. (21)). The experimental and numerical temperature profiles plotted in Fig. 9 show a good agreement in the case that soot radiation is included. As expected, soot radiation starts to play a predominant role at heights with relevant soot concentrations (see Fig. 11). The largest discrepancies observed are in the lower part of the flame, directly downstream of the burner. Preheating effects could be a possible explanation for these errors although simulations performed with higher inlet temperatures (not shown here) did not show substantial improvements. It should be also kept in mind that thermocouple measurements in the fuel-rich region may be affected by conduction errors, as the support has to pass through the flame front [10]. Another possible reasons for the delay of the temperature rise could be deficiencies in the chemistry for fuel-rich conditions. Moreover, the model is not able to reproduce the temperature drop at $x \approx 4 \mathrm{~cm}$ and at the moment, the reasons for these differences are not clear. However, because 
this tendency is more pronounced for more sooting flames (e.g. lower premixing ratios [22]) it could be related to soot radiation.

Methane, acetylene and benzene axial profiles are plotted in Fig. 10. Again, the agreement between experimental and numerical data is excellent. A remarkable yet unexpected behaviour is the insensitivity of these profiles to soot radiation despite the fact, that large temperature variations (up to $200 \mathrm{~K}$ ) occur. Only a slight shift in acetylene and benzene concentrations is observed. While the methane peak is slightly overpredicted, its location matches very well. The agreement in acetylene and benzene concentrations is excellent, both in peak position and overall trend. When compared to the experiments, the acetylene profiles are slightly shifted upstream, while benzene inception is somewhat delayed. However, these differences are within the experimental errors $(1 \mathrm{~mm}$ for probe position, $30 \%$ for species measurements).

Finally, soot volume fraction profiles are given in Fig. 11 where numerical values are compared with LII measurements. Again, an outstanding agreement is attained since soot volume fraction maxima differ by about $15 \%$ only, and the locations of the soot volume fraction peaks match perfectly. It has to be pointed out that these results are achieved without any further adjustment of the soot model constants.

\subsection{Kerosene surrogate/air flame}

The last benchmark for the new soot model is a laminar diffusion flame burning a surrogate of kerosene. This experiment was performed by Moss and Aksit [21] and is one of the few examples where a complex fuel (or a surrogate of it) is used for running a laminar, heavily sooting diffusion flame. The experiment was conducted under atmospheric conditions and no flame confinement was applied. In order to avoid uncertainties with respect to the composition of real kerosene, a two-component model fuel ( $77 \%$ n-decane, $23 \%$ mesitylene, by 
volume) was employed. As the experimental setup presented several difficulties (pre-evaporation of the fuel, heavily sooting conditions), radial temperature and soot measurements are available at three axial positions only.

Inflow and boundary conditions for this flame are summarised in Table 6 . The determination of the fuel inlet conditions was not unambiguous. To our knowledge there is no detailed reaction mechanism in literature which is able to model mesitylene combustion. Therefore, this component has been replaced by benzene, as recommended and done by Moss and Aksit [21] too. The inlet compositions and temperature are taken from the same work. In order to determine the correct mass flow (benzene has a different density), the inlet velocity is adjusted in a way that a good agreement with the first radial temperature profile (measured at $x=20 \mathrm{~mm}$ ) is obtained. In this way a correct prediction of the flame shape and of the residence time of the soot particles in the fuel-rich region is achieved. Although it can be argued that benzene has a special role in the model formulation (Eq. 1), it should be pointed out that the chemical kinetics mechanism employed for this simulation [28] also includes reactions which are in competition with $\mathrm{PAH}$ formation step. Although the interaction among these steps is complex and mostly still under research, it is modeled properly as a good agreement with the experimental data is achieved without any further model tuning.

Simulations are carried out on a hexahedral grid with 250x90 elements in axial and radial direction, respectively. A fully developed laminar inlet profile for the velocity is assumed at the fuel inlet, whereas a constant value is set for the air. Again, all parameters and constants of the PAH and soot model are kept constant and correspond to the values given in Table 3. Soot radiation according to Eq. (21) is included in the simulation. 


\subsubsection{Temperature and soot profiles}

Radial profiles of temperature at heights of 20,30 and $40 \mathrm{~mm}$ above the burner are plotted in Fig. 12. The temperature prediction at $20 \mathrm{~mm}$ matches the experimental data very well, as boundary conditions are calibrated accordingly. However, good predictions are also obtained at the other positions and both flame thickness and peak temperature are reproduced well. The simulations which take soot radiation into account (solid lines) are in better agreement with the experimental data. The minor shift at $x=40 \mathrm{~mm}$ between the experimental and numerical peak temperatures can be explained by the higher inlet velocity imposed (benzene is lighter than mesitylene).

Experimental and numerical radial soot profiles are shown in Fig. 13. In comparison with the previous testcases where $\mathrm{C}_{1}$ and $\mathrm{C}_{2}$ fuels have been employed, the soot volume fractions are now between one and two order of magnitude higher. Nevertheless, the soot model again achieves excellent predictions at all positions. Widths and peaks of the soot distributions are within the range of experimental errors. The largest error is observed at $x=20 \mathrm{~mm}$, where the soot peak values are overpredicted by a factor of about two. Reasons for these discrepancies are not further investigated, as no experimental data for intermediate species and soot precursors are available.

\section{Conclusions}

A new soot formation model for gas turbine applications is presented and validated. A general framework is used, where a finite-rate chemistry combustion model is coupled to a sectional approach for Polycyclic Aromatic Hydrocarbons (PAHs). The two-equation model for the soot volume fraction and soot particle number density is coupled by the PAH transport equations with the gas phase. The model includes all physically relevant processes as nucleation, growth and 
oxidation. As the computational effort for solving the additional PAH and soot transport equations is relatively small, the model is still suited for gas turbine applications.

An extensive validation of the proposed model has been presented, and flames running different fuels ranging from methane to a surrogate kerosene have been simulated. Moreover, both pure-diffusion and partially-premixed regimes have been investigated. This requires the use of different kinetic mechanisms for the gas phase. However, all parameters used in the soot model are validated using the well investigated methane diffusion flame and no further tuning has been performed for the simulation of the other flames. By comparison with the experimental data it has been shown that the model is able to attain a high degree of accuracy in temperature, species and soot concentrations, independently from the fuel used or from the burning regime.

\section{Acknowledgements}

This work has been partially financed by the European Union through the Framework Sixth programme "SiA-TEAM". The authors wish to thank T. Blacha, Dr. E. Goos and Dr. N. Slavinskaya for their helpful assistance in implementing the kinetic mechanisms.

\section{References}

[1] A. Wulff, J. Hourmouziadis, Technology Review of Aeroengine Pollutant Emissions, Aerospace Science and Technology 8 (1997) 557-572.

[2] W. Lazik, T. Doerr, S. Bake, R. Bank, L. Rackwitz, Development of a Lean-Burn Low-NOx Combustion Technology at Rolls-Royce Deutschland, ASME paper GT2008-51115. 
[3] F. Mauss, T. Schäfer, H. Bockhorn, Inception and Growth of Soot Particles in Dependence on the Surrounding Gas Phase, Combustion and Flame 99 (1994) 697-705.

[4] J. Appel, H. Bockhorn, M. Frenklach, Kinetic Modeling of Soot Formation with Detailed Chemistry and Physics: Laminar Premixed Flames of $\mathrm{C}_{2}$ Hydrocarbons, Combustion and Flame 121 (2000) 122-136.

[5] J. Appel, H. Bockhorn, M. Wulkow, A Detailed Numerical Study of the Evolution of Soot Particle Size Distribution in Laminar Premixed Flames, Chemosphere 42 (2001) 635-645.

[6] S. Granata, F. Cambianica, S. Zinesi, T. Faravelli, E. Ranzi, Detailed Kinetics of PAH and Soot Formation in Combustion Processes: Analogies and Similarities in Reaction Classes, in: Proceedings of the European Combustion Meeting, 2005.

[7] H. Richter, S. Granata, W. Green, D. Kronholm, J. Howard, Detailed Modeling of PAH and Soot Formation in Flames, in: Proceedings of the European Combustion Meeting, 2003.

[8] H. Richter, M. Braun-Unkhoff, S. Granata, J. Yu, E. Goos, N. Slavinskaya, P. Frank, W. Green, J. Howard, Computational Investigation of PAH and Soot Formation in Premixed Ethylene Flames, in: Proceedings of the European Combustion Meeting, 2005.

[9] A. Kazakov, H. Wang, M. Frenklach, Detailed Modeling of Soot Formation in Laminar Premixed Ethylene Flames at a Pressure of 10 bar, Combustion and Flame 100 (1995) 111-120.

[10] C. McEnally, A. Schaffer, M. Long, L. Pfefferle, M. Smooke, M. Colket, R. Hall, Computational and Experimental Study of Soot Formation in a Co- 
flow, Laminar, Ethylene Diffusion Flame, in: Twenty-Seventh Symposium (International) on Combustion, 1998, pp. 1497-1595.

[11] B. Zhao, Z. Yang, M. Johston, H. Wang, A. Wexler, M. Balthasar, M. Kraft, Measurements and Numerical Simulation of Soot Particle Size Distribution Functions in a Laminar Premixed Ethylene-Oxygen-Argon Flame, Combustion and Flame 133 (2003) 173-188.

[12] I. Kennedy, W. Kollmann, Prediction of Soot in Laminar Diffusion Flames, AIAA Journal 29 (9) (1991) 1452-1457.

[13] P. R. Lindstedt, Simplified Soot Nucleation and Surface Growth Steps for Non-Premixed Flames, in: H. Bockhorn (Ed.), Soot Formation in Combustion, Springer Series in Chemical Physics, Springer-Verlag, 1994.

[14] B. Zamuner, F. Dupoirieux, Numerical Simulation of Soot Formation in a Turbulent Flame with a Monte-Carlo PDF Approach and Detailed Chemistry, Combustion Science and Technology 158 (2000) 407-438.

[15] W. Tsang, Important Factors in the Development of Combustion Mechanisms for Realistic Fuels, AIAA paper 2002-1098.

[16] A. El-Leathy, F. Xu, G. Faeth, Soot Surface Growth and Oxidation in Laminar Unsaturated-Hydrocarbon/Air Diffusion Flames, AIAA-paper 20021116.

[17] X. El-Leathy, A.M., Soot Surface Growth in Laminar Hydrocarbon/Air Diffusion Flames, AIAA Journal 41 (5) (2003) 856-865.

[18] C. Kaplan, K. Kailasanath, Flow-field Effects on Soot Formation in Normal and Inverse Methane-Air Diffusion Flames, Combustion and Flame 124 (2001) 275-294. 
[19] K. Thomson, L. G. Ömer, J. W. Elizabeth, R. Fraser, G. Smallwood, D. Snelling, Soot Concentration and Temperature Measurements in Coanular, Nonpremixed $\mathrm{CH}_{4}$ /air Laminar Flames at Pressure up to $4 \mathrm{MPa}$, Combustion and Flame 140 (2005) 222-232.

[20] H. Guo, F. Liu, G. Smallwood, Soot and NO Formation in Counterflow Ethylene/Oxygen/Nitrogen Diffusion Flames, Combustion Theory and Modeling 8 (2004) 475-489.

[21] J. Moss, I. Aksit, Modelling soot formation in a laminar diffusion flame burning a surrogate kerosen fuel, in: Proceedings of the Combustion Institute, Vol. 31, The Combustion Institute, 2007, pp. 3139-3146.

[22] C. McEnally, A. Pfefferle, Experimental Study of Nonfuel Hydrocarbons and Soot in Coflowing Partially Premixed Ethylene/Air Flames, Combustion and Flame 121 (2000) 575-592.

[23] B. Bennet, C. McEnaly, L. Pfefferle, M. Smooke, Computational and Experimental Study of Axisymmetric Coflow Partially Premixed Methane/Air Flames, Combustion and Flame 123 (2000) 522-546.

[24] H. Guo, F. Liu, G. Smallwood, O. Gülder, Numerical Study on the Influence of Hydrogen Addition on Soot Formation in a Laminar Ethylene-Air Diffusion Flame, Combustion and Flame 145 (2006) 324-338.

[25] D. A. Bittker, Detailed Mechanism for Oxidation of Benzene, Combustion Science and Tecnology 79 (1991) 49-72.

[26] A. D'Anna, J. H. Kent, Aromatic Formation Pathways in Non-Premixed Methane Flames, Combustion and Flame 132 (2003) 715-722.

[27] J. H. S. S. Knystautas, R. Lee, Flame Acceleration and Transition to Detonation in Benzene-Air Mixtures, Combustion and Flame 115 (1998) 424-436. 
[28] N. Slavinskaya, Skeletal Mechanism for Kerosene Combustion with PAH Production, AIAA paper 2008-992.

[29] M. Castaldi, A. Vincitore, S. Senkan, Micro-structures of Premixed Hydrocarbon Flames: Methane, Combustion Science and Technology 107 (1995) $1-19$.

[30] J. Miller, The Kinetics of Polynuclear Aromatic Hydrocarbon Agglomeration in Flames, in: The Combustion Institute (Ed.), Twenty-Third Symposium (International) on Combustion, 1990, pp. 91-98.

[31] M. Skjøth-Rasmussen, P. Glarborg, M. Østberg, J. Johanness, Livbjerg. H., A. Jensen, T. Christensen, Formation of Polycyclic Aromatic Hydrocarbons and Soot in Fuel-rich Oxidation of Methane in a Laminar Flow Reactor, Combustion and Flame 136 (2004) 91-128.

[32] B. Öktem, M. Tolocka, B. Zhao, H. Wang, M. Johnston, Chemical species associated with the early stage of soot growth in a laminar premixed ethylene-oxygen-argon flame, Combustion and Flame 142 (2005) 364-374.

[33] M. Frenklach, Computer Modeling of Infinite Reaction Sequences: a Chemical Lumping, Chemical Engineering Science 40 (10) (1984) 1843-1849.

[34] M. Di Domenico, Numerical Simulation of Soot Formation in Turbulent Flows, Phd thesis, University of Stuttgart (2008).

[35] H. Bockhorn (Ed.), Soot Formation in Combustion: Mechanism and Models, Springer Verlag, Berlin, 1994.

[36] I. Kennedy, C. Yam, D. Rapp, R. Santoro, Modeling and Measurements of Soot and Species in a Laminar Diffusion Flame, Combustion and Flame 107 (1996) 368-382. 
[37] J. Moss, C. Stewart, K. Young, Modeling Soot Formation and Burnout in a High Temperature Laminar Diffusion Flame Burning under OxygenEnriched Conditions, Combustion and Flame 101 (1995) 491-500.

[38] Z. Wen, S. Yun, M. Thomson, M. Lightstone, Modelling Soot Formation in Turbulent Kerosene/Air Jet Diffusion Flames, Combustion and Flame 135 (2003) 323-340.

[39] H. Bockhorn, Soot formation in combustion, Springer, 1994.

[40] T. Santoro, T. Yeh, J. Horvath, H. Semerjian, The Transport and Growth of Soot Particles in Laminar Diffusion Flames, Combustion Science and Technology 53 (1987) 89-115.

[41] M. Di Domenico, P. Gerlinger, M. Aigner, Numerical Investigation of Soot Formation in Laminar Ethylene-Air Diffusion Flames, ASME paper GT2007-27118.

[42] S. Patankar, Numerical Heat Transfer and Fluid Flow, Series in Computational Methods in Mechanics and Thermal Science, Hemisphere Publishing Corporation, 1980.

[43] M. D. Smooke, C. S. McEnally, L. Pfefferle, R. Hall, M. Colket, Computational and Experimental Study of Soot Formation in a Coflow, Laminar Diffusion Flame, Combustion and Flame 117 (1999) 117-139.

[44] O. Gülder, K. Thomson, D. Snelling, Effect of Fuel Nozzle Material Properties on Soot Formation and Temperature Field in Coflow Laminar Diffusion Flames, Combustion and Flame 144 (2006) 426-633.

[45] H. Guo, F. Liu, G. Smallwood, O. Gülder, The Flame Preheating Effect on Numerical Modelling of Soot Formation in a Two-Dimensional Laminar 
Ethylene-Air Diffusion Flame, Combustion Theory and Modelling 6 (2002) $173-187$.

[46] C. S. McEnally, Ömit Ö. Köylü, L. D. Pfefferle, D. E. Rosner, Soot volume fraction and temperature measurements in laminar nonpremixed flames using thermocouples, Combustion and Flame 109 (4) (1997) $701-720$.

[47] M. Smooke, M. Long, B. Connelly, M. Colket, R. Hall, Soot Formation in Laminar Diffusion Flames, Combustion and Flame 143 (2005) 613-628.

[48] L. Sgro, A. D. Filippo, G. Lanzuolo, A. D'Alessio, Characterization of nanoparticles of organic carbon (noc) produced in rich premixed flames by differential mobility analysis, Proceedings of the Combustion Institute 31 (1) (2007) $631-638$.

[49] K. Claramunt, R. Cònsul, C. Pérez-Segarra, A. Oliva, Multidimensional Mathematical Modeling and Numerical Investigation of Co-flow Partially Premixed Methane/Air Laminar Flames, Combustion and Flame 137 (2004) 444-457.

[50] J. Singh, R. Patterson, M. Kraft, H. Wang, Numerical Simulation and Sensitivity Analysis of Detailed Soot Particle Size Distribution in Laminar Premixed Ethylene Flames, Combustion and Flame 145 (2006) 117-127.

[51] D. Bento, K. Thomson, O. Gülder, Soot Formation and Temperature Field Structure in Laminar Propane-Air Diffusion Flames at Elevated Pressures, Combustion and FlameIn press.

[52] A. D'Anna, J. Kent, Modeling of Particulate Carbon and Species Formation in Coflowing Diffusion Flames of Ethylene, Combustion and Flame 144 (2006) 249-260. 


\section{List of Figures}

1 Basic combustion steps from fuel break-up to soot. . . . . . . . 36

2 PAH distributions extracted at two different positions of a methane diffusion flame. . . . . . . . . . . . . . . . 37

3 Experimental and numerical temperature profiles at several heights above the burner for the methane/air flame of Smooke et al. [43]. Symbols: measurement, solid line: ABF mechanism w/o soot model, dotted line: ABF mechanism (4 PAH classes), dash-dot line: Bittker mechanism. . . . . . . . . . . . . . . .

4 Experimental and numerical acetylene profiles at several heights above the burner for the methane/air flame of Smooke et al. [43]. Symbols: measurement, solid line: ABF mechanism w/o soot model, dashed line: ABF mechanism (4 PAH classes), dotted line: $\mathrm{ABF}$ mechanism (8 PAH classes), dash-dot line: Bittker mechanism. . . . . . . . . . . . . . . .

$5 \quad$ Experimental and numerical benzene profiles at several heights above the burner for the methane/air flame of Smooke et al. [43]. Symbols: measurement, solid line: ABF mechanism w/o soot model, dashed line: ABF mechanism (4 PAH classes), dotted line: $\mathrm{ABF}$ mechanism (8 PAH classes), dash-dot line: Bittker mechanism. . . . . . . . . . . . . . . . .

6 Experimental and numerical soot volume fraction profiles at several heights above the burner for the methane/air flame of Smooke et al. [43]. Symbols: measurement, solid line: ABF mechanism (4 PAH classes), dotted line: ABF mechanism (8 PAH classes), dash-dot line: Bittker mechanism, dashed line + symbols: simulation from Ref. [43]. . . . . . . . . . . . . . . . . . . 41

7 Computed distributions of soot precursor $\mathrm{PAH}_{1}$ to $\mathrm{PAH}_{4}$ for the $\mathrm{CH}_{4}$ /air diffusion flame of Smooke et al. [43]. . . . . . . . . . . 42

8 Computed soot number density (normalised) and soot volume fraction distributions for the $\mathrm{CH}_{4}$ /air diffusion flame of Smooke et al. [43]. . . . . . . . . . . . . . . . .

9 Experimental and numerical axial temperature profiles for the ethylene/air diffusion flame of McEnally et al. [22]. Symbols: measurement, solid line: numerical simulation with soot radiation, dashed lines: numerical simulation without soot radiation.

10 Experimental and numerical axial methane, acetylene and benzene profiles for the ethylene/air diffusion flame of McEnally et al. [22]. Symbols: measurement, solid line: numerical simulation with soot radiation, dashed lines: numerical simulation without soot radiation. 
11 Experimental and numerical axial soot volume fraction profiles for the ethylene/air diffusion flame of McEnally et al. [22]. Symbols: measurement, solid line: numerical simulation with soot radiation, dashed lines: numerical simulation without soot radi-

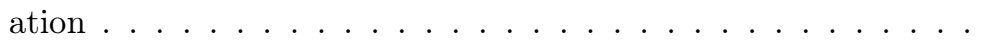

12 Experimental and numerical radial temperature profiles for the kerosene/air diffusion flame of Moss and Aksit [21]. Symbols: measurement, solid line: numerical simulation with soot radiation, dashed lines: numerical simulation without soot radiation.

13 Experimental and numerical radial temperature profiles for the kerosene/air diffusion flame of Moss and Aksit [21]. Symbols: measurement, solid line: numerical simulation with soot radiation, dashed lines: numerical simulation without soot radiation. 


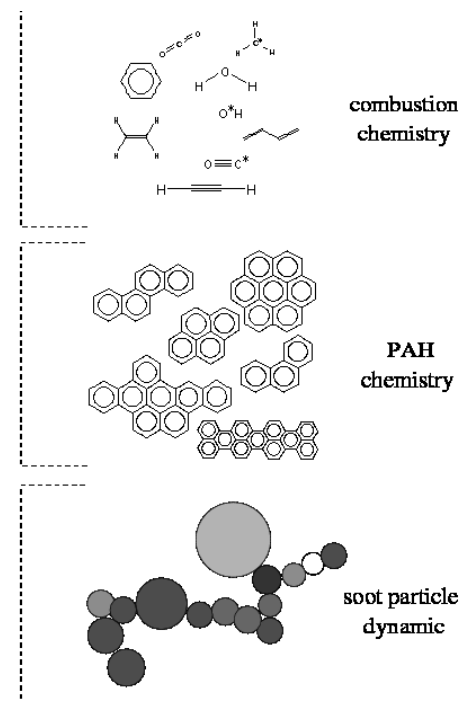

Figure 1: Basic combustion steps from fuel break-up to soot. 


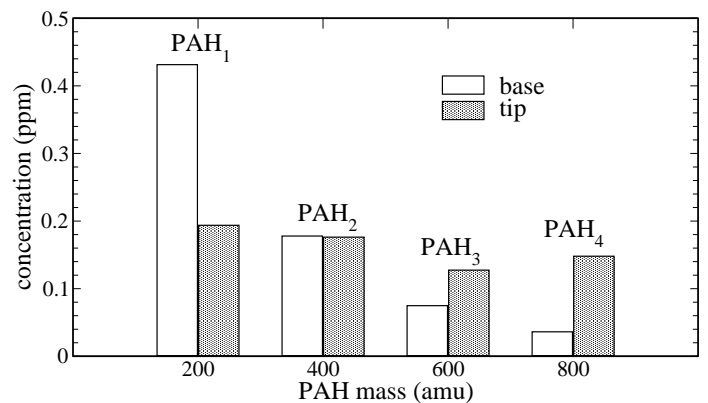

Figure 2: PAH distributions extracted at two different positions of a methane diffusion flame. 


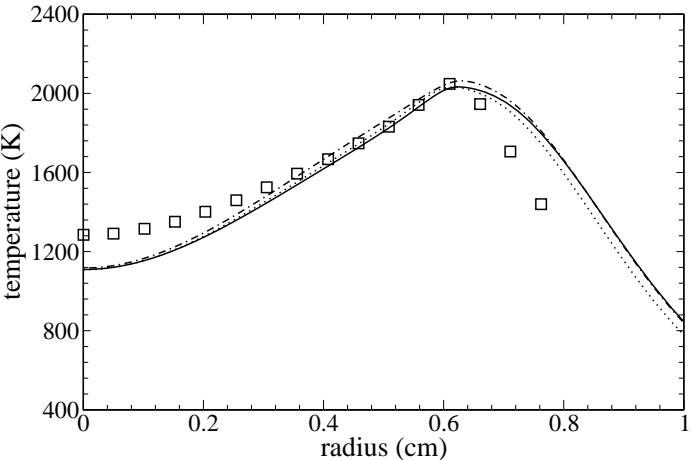

(a) $1.0 \mathrm{~cm}$

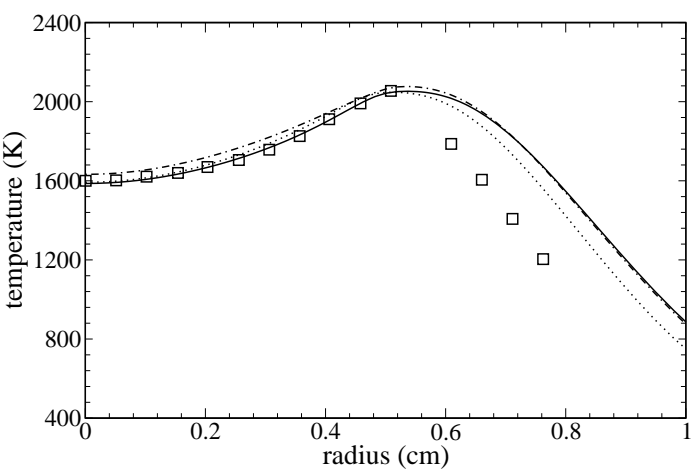

(c) $2.0 \mathrm{~cm}$

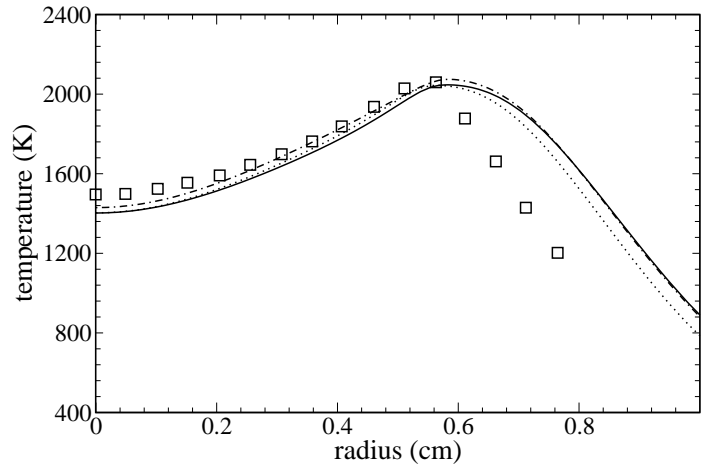

(b) $1.5 \mathrm{~cm}$

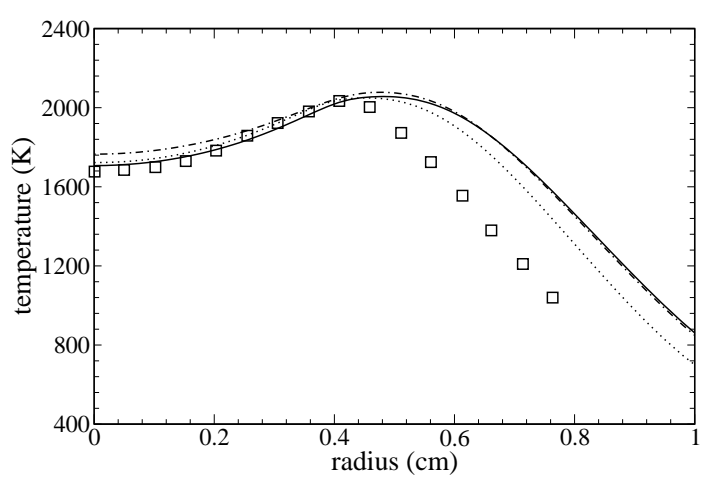

(d) $2.5 \mathrm{~cm}$

Figure 3: Experimental and numerical temperature profiles at several heights above the burner for the methane/air flame of Smooke et al. [43]. Symbols: measurement, solid line: $\mathrm{ABF}$ mechanism w/o soot model, dotted line: $\mathrm{ABF}$ mechanism (4 PAH classes), dash-dot line: Bittker mechanism. 


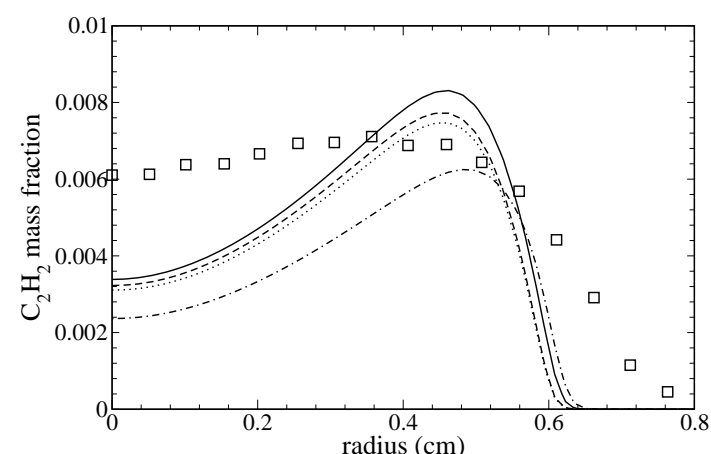

(a) $1.0 \mathrm{~cm}$

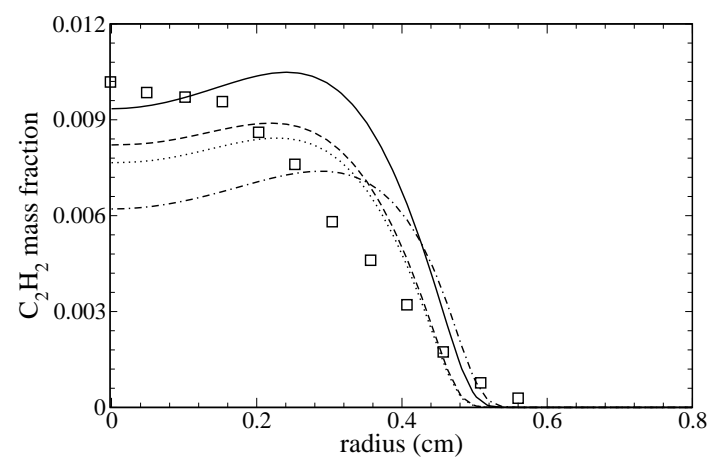

(c) $2.0 \mathrm{~cm}$

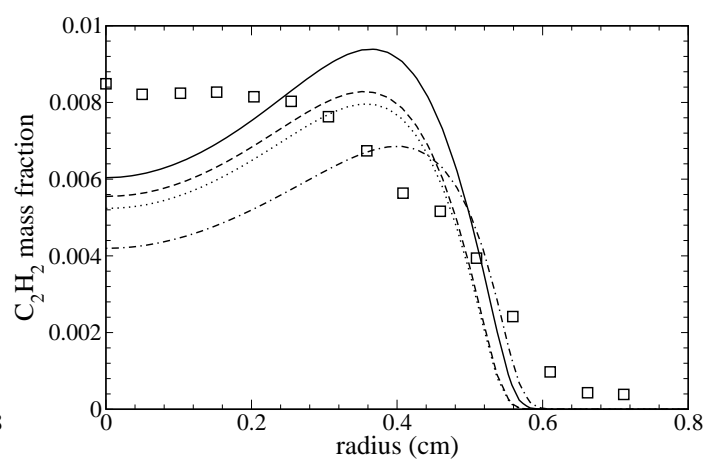

(b) $1.5 \mathrm{~cm}$

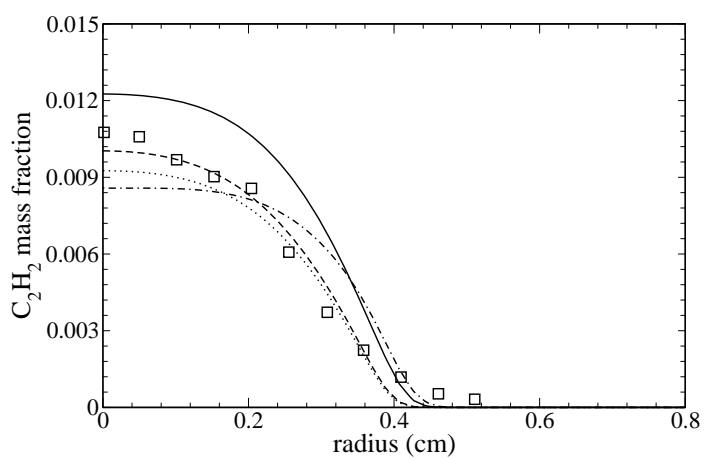

(d) $2.5 \mathrm{~cm}$

Figure 4: Experimental and numerical acetylene profiles at several heights above the burner for the methane/air flame of Smooke et al. [43]. Symbols: measurement, solid line: ABF mechanism w/o soot model, dashed line: ABF mechanism (4 PAH classes), dotted line: ABF mechanism (8 PAH classes), dash-dot line: Bittker mechanism. 


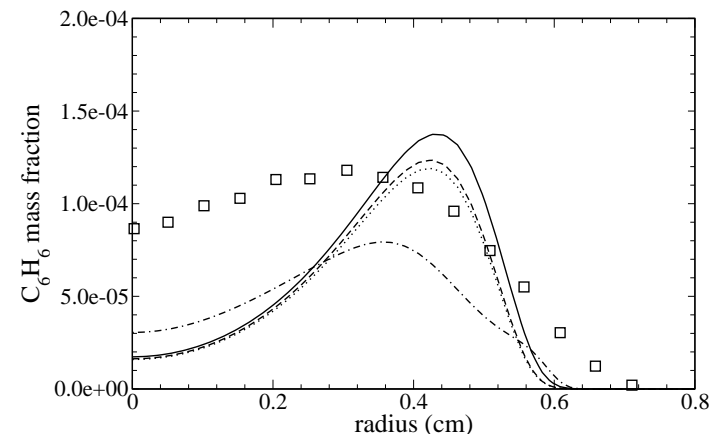

(a) $1.0 \mathrm{~cm}$

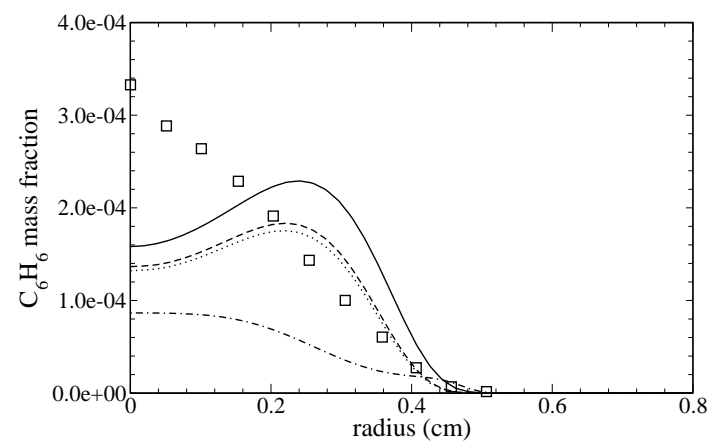

(c) $2.0 \mathrm{~cm}$

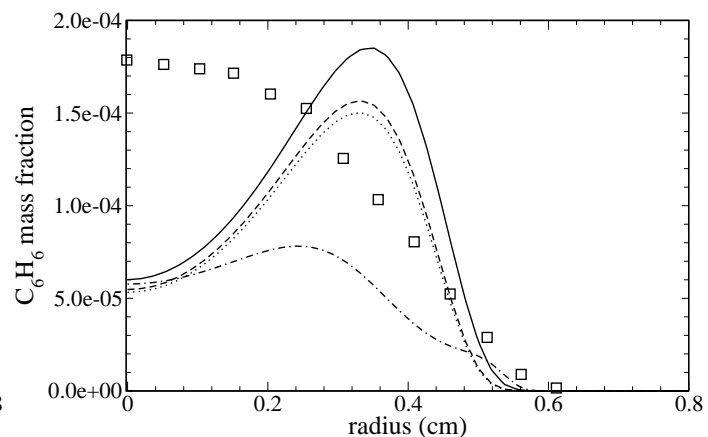

(b) $1.5 \mathrm{~cm}$

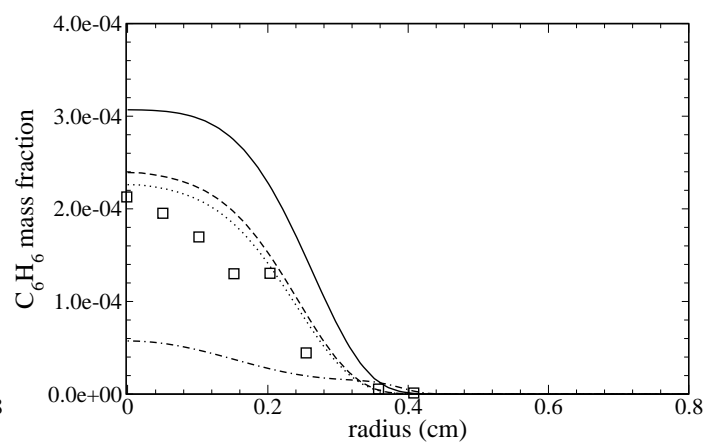

(d) $2.5 \mathrm{~cm}$

Figure 5: Experimental and numerical benzene profiles at several heights above the burner for the methane/air flame of Smooke et al. [43]. Symbols: measurement, solid line: ABF mechanism w/o soot model, dashed line: ABF mechanism (4 PAH classes), dotted line: ABF mechanism (8 PAH classes), dash-dot line: Bittker mechanism. 


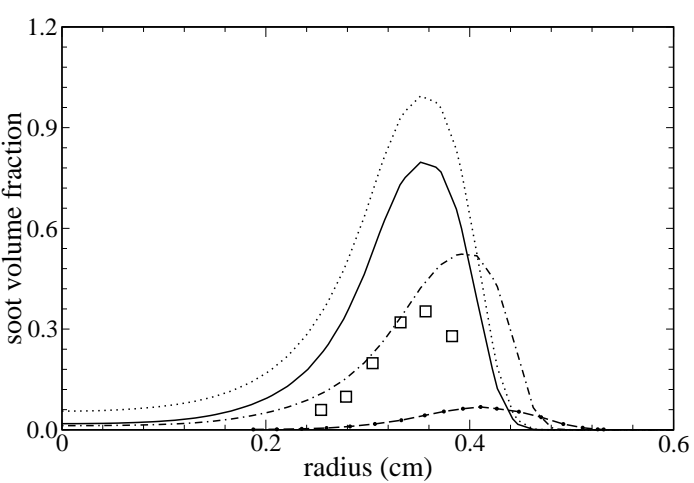

(a) $2.0 \mathrm{~cm}$

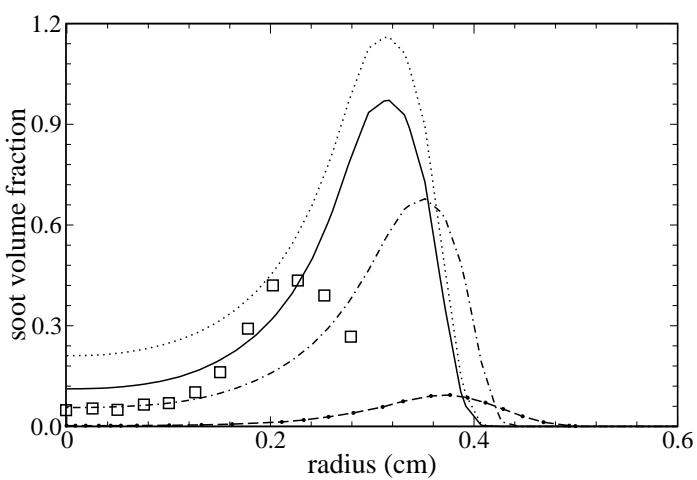

(c) $2.5 \mathrm{~cm}$

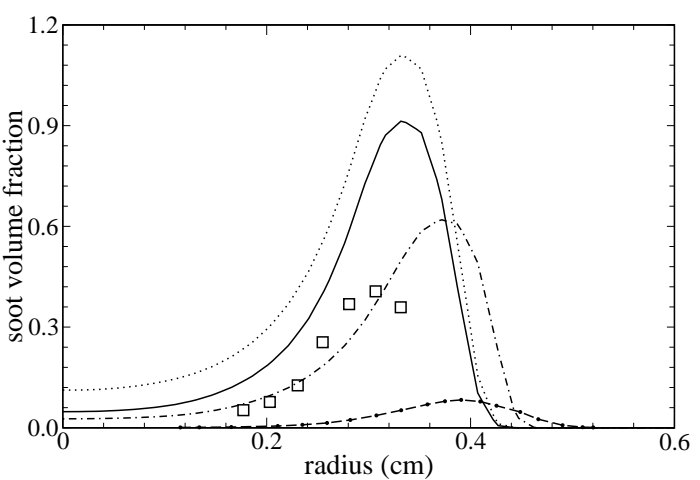

(b) $2.25 \mathrm{~cm}$

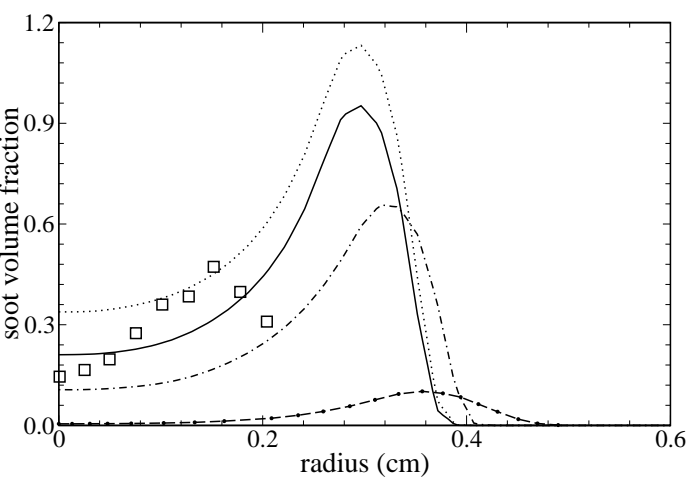

(d) $2.75 \mathrm{~cm}$

Figure 6: Experimental and numerical soot volume fraction profiles at several heights above the burner for the methane/air flame of Smooke et al. [43]. Symbols: measurement, solid line: ABF mechanism (4 PAH classes), dotted line: ABF mechanism (8 PAH classes), dash-dot line: Bittker mechanism, dashed line + symbols: simulation from Ref. [43]. 


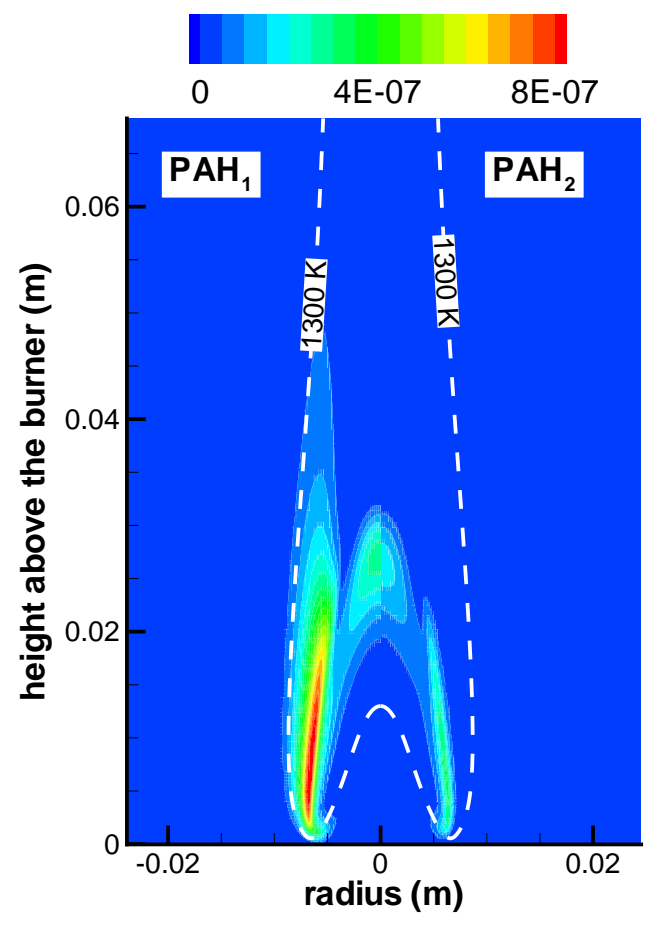

(a)

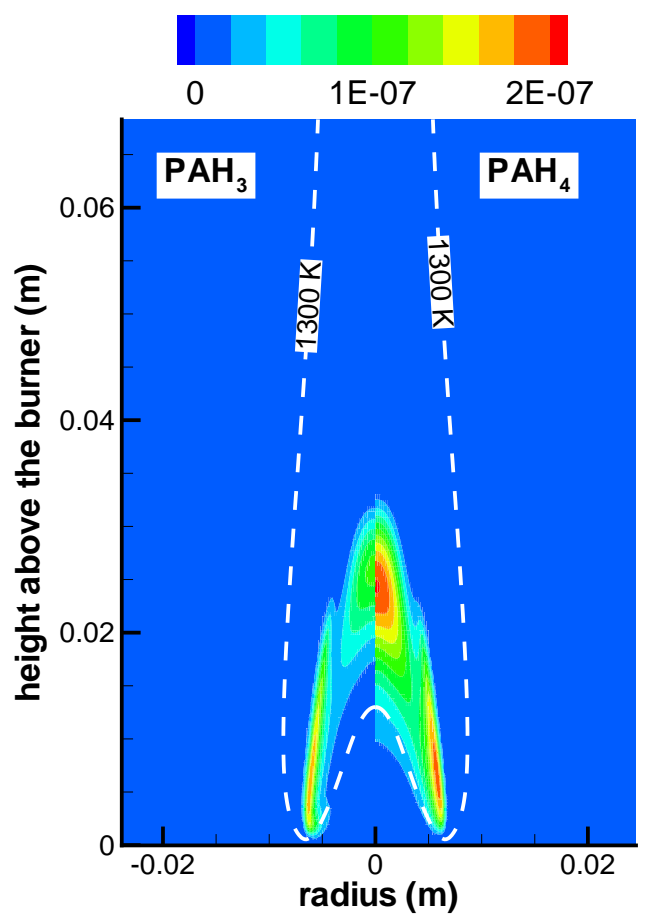

(b)

Figure 7: Computed distributions of soot precursor $\mathrm{PAH}_{1}$ to $\mathrm{PAH}_{4}$ for the $\mathrm{CH}_{4} /$ air diffusion flame of Smooke et al. [43]. 


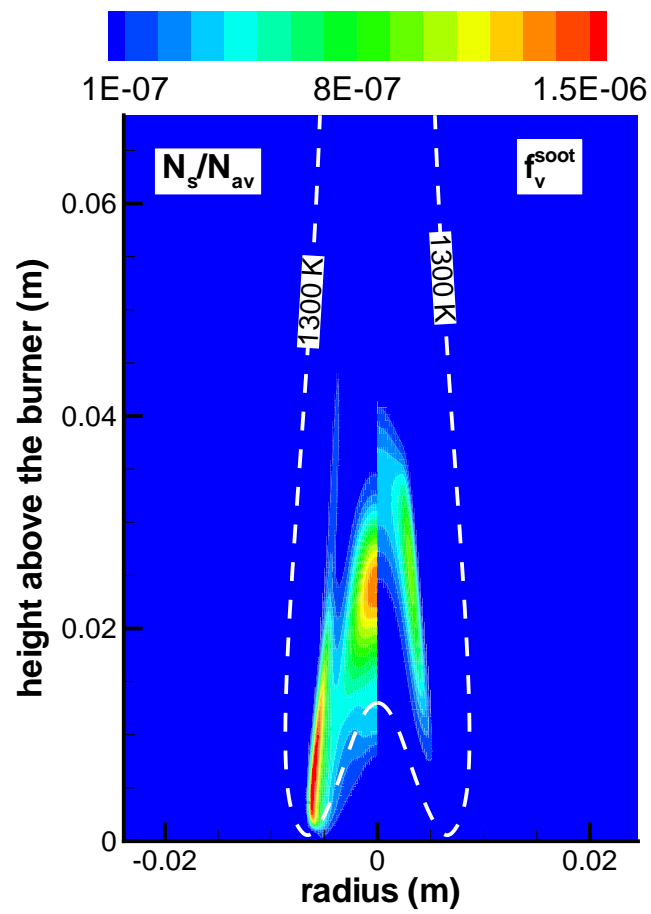

Figure 8: Computed soot number density (normalised) and soot volume fraction distributions for the $\mathrm{CH}_{4}$ /air diffusion flame of Smooke et al. [43]. 


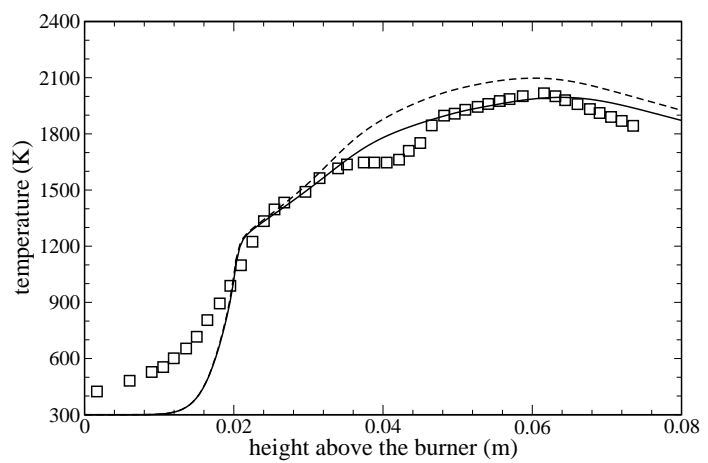

Figure 9: Experimental and numerical axial temperature profiles for the ethylene/air diffusion flame of McEnally et al. [22]. Symbols: measurement, solid line: numerical simulation with soot radiation, dashed lines: numerical simulation without soot radiation. 


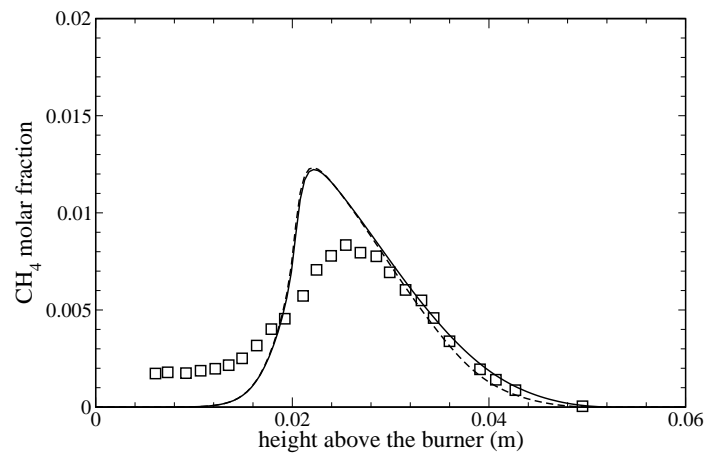

(a) $\mathrm{CH}_{4}$

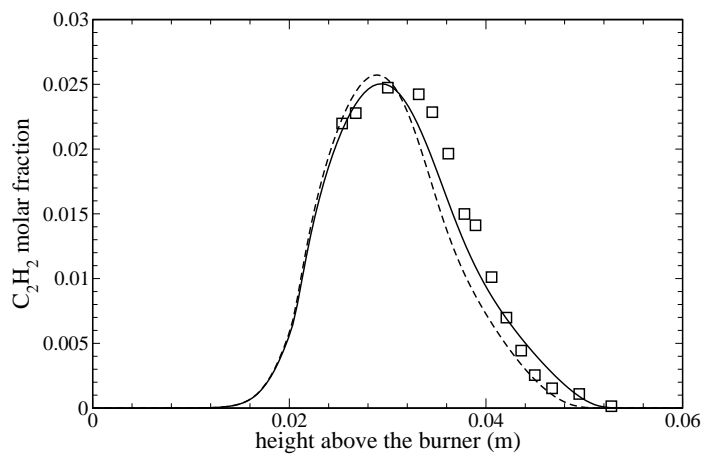

(b) $\mathrm{C}_{2} \mathrm{H}_{2}$

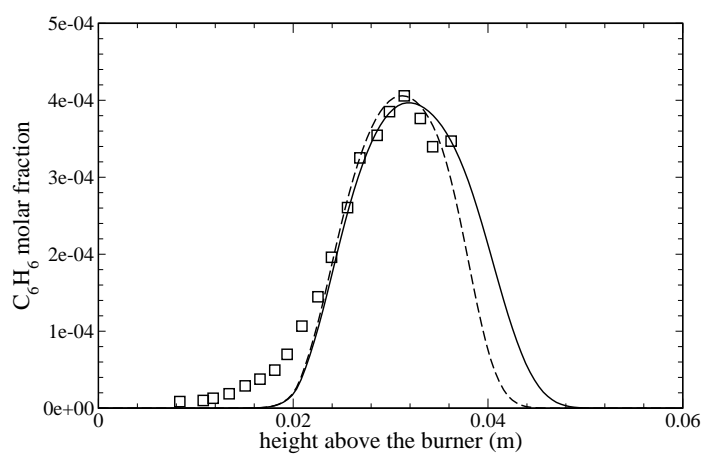

(c) $\mathrm{C}_{6} \mathrm{H}_{6}$

Figure 10: Experimental and numerical axial methane, acetylene and benzene profiles for the ethylene/air diffusion flame of McEnally et al. [22]. Symbols: measurement, solid line: numerical simulation with soot radiation, dashed lines: numerical simulation without soot radiation. 


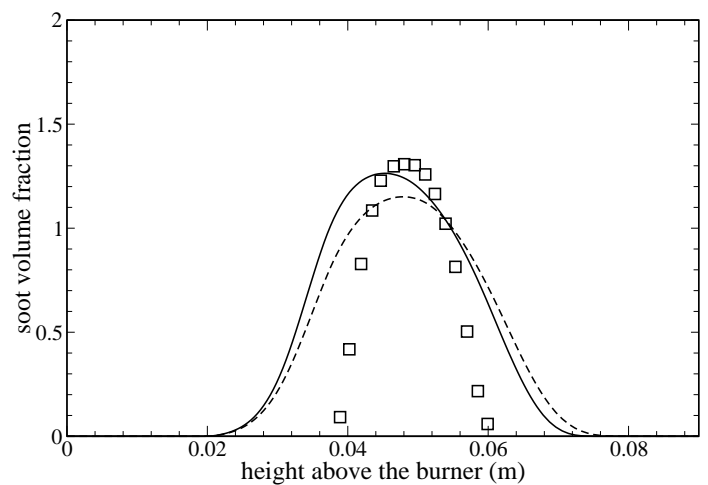

Figure 11: Experimental and numerical axial soot volume fraction profiles for the ethylene/air diffusion flame of McEnally et al. [22]. Symbols: measurement, solid line: numerical simulation with soot radiation, dashed lines: numerical simulation without soot radiation 


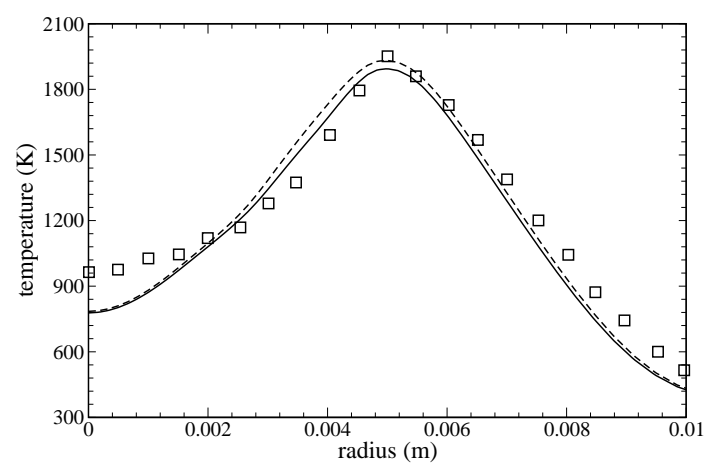

(a) $20 \mathrm{~mm}$

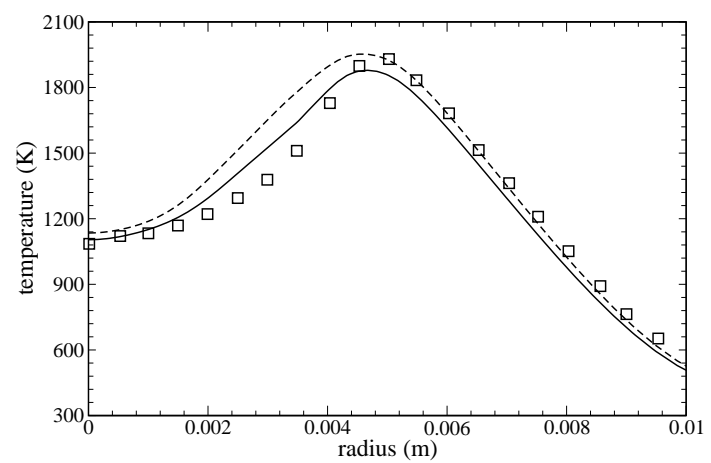

(b) $30 \mathrm{~mm}$

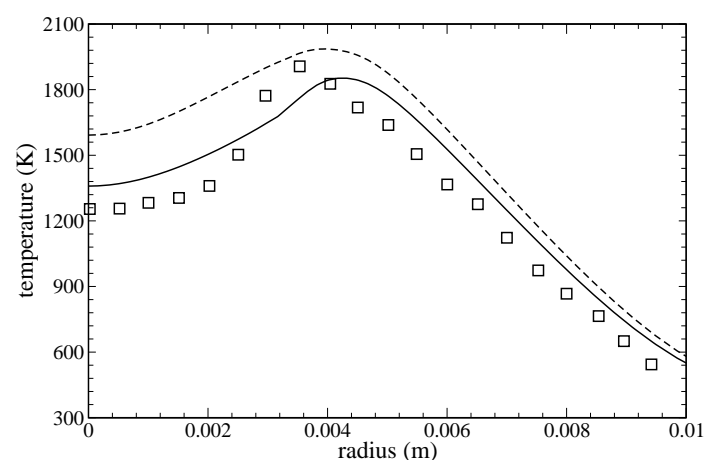

(c) $40 \mathrm{~mm}$

Figure 12: Experimental and numerical radial temperature profiles for the kerosene/air diffusion flame of Moss and Aksit [21]. Symbols: measurement, solid line: numerical simulation with soot radiation, dashed lines: numerical simulation without soot radiation. 


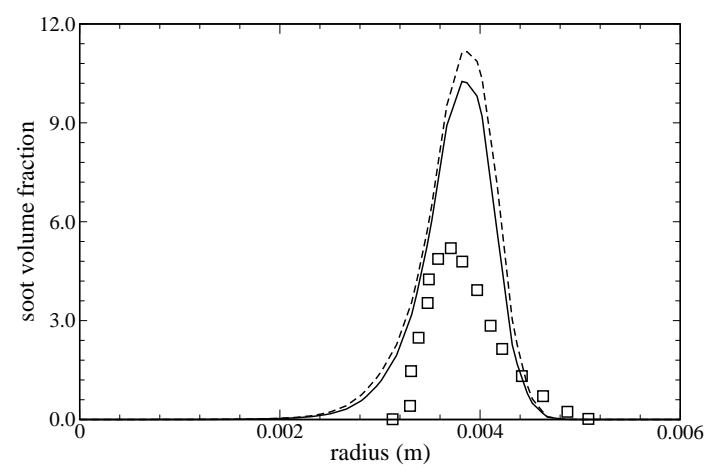

(a) $20 \mathrm{~mm}$

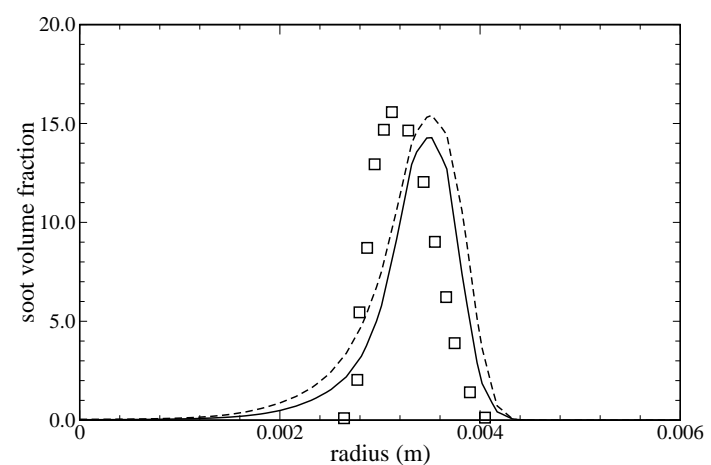

(b) $30 \mathrm{~mm}$

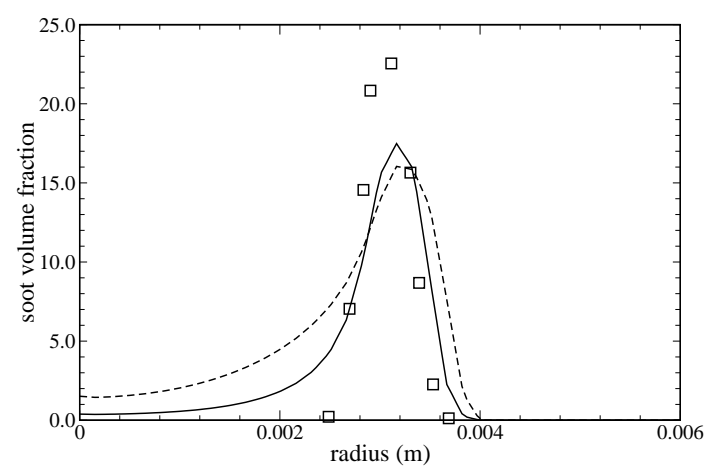

(c) $40 \mathrm{~mm}$

Figure 13: Experimental and numerical radial temperature profiles for the kerosene/air diffusion flame of Moss and Aksit [21]. Symbols: measurement, solid line: numerical simulation with soot radiation, dashed lines: numerical simulation without soot radiation. 


\section{List of Tables}

1 Chemical kinetics mechanisms used. . . . . . . . . . . . . 50

2 Overview of PAH source terms and their use in the PAH transport equations ..................... 51

3 Constants used in the soot formation model. Units are mol, m, s, K. . . . . . . . . . . . . . . . . . . . 52

4 Boundary conditions for the methane/air flame of Smooke et al. 53

5 Boundary conditions for the ethylene/air flame of McEnally et al. [22]. . . . . . . . . . . . . . . . . . . . . . 54

6 Boundary conditions for the simulation of the kerosene surrogate/air flame of Moss and Aksit [21]. . . . . . . . . . . . 55 
Table 1: Chemical kinetics mechanisms used.

\begin{tabular}{ccccc}
\hline Fuel mixture & $\begin{array}{c}\text { Kinetic } \\
\text { mechanism }\end{array}$ & \# of species & \# of reactions & Ref. \\
\hline $\mathrm{CH}_{4}$ & $\begin{array}{c}\text { Appel, } \\
\text { Bockhorn, } \\
\text { Frenklach }\end{array}$ & 71 & 394 & {$[4]$} \\
\hline $\mathrm{CH}_{4}$ & Bittker & 39 & 128 & {$[25,26,27]$} \\
\hline $\mathrm{C}_{2} \mathrm{H}_{4} / \mathrm{N}_{2}$ & $\begin{array}{c}\text { Appel, } \\
\text { Bockhorn, } \\
\text { Frenklach }\end{array}$ & 71 & 394 & {$[4]$} \\
\hline $\begin{array}{c}\text { kerosene } \\
\text { (surrogate) }\end{array}$ & Slavinskaya & 40 & 169 & {$[28]$} \\
\hline
\end{tabular}


Table 2: Overview of PAH source terms and their use in the PAH transport equations

\begin{tabular}{|c|c|c|c|}
\hline Source term & $\mathrm{PAH}_{1}$ & $\mathrm{PAH}_{2 \ldots N_{p}-1}$ & $\mathrm{PAH}_{N_{p}}$ \\
\hline \hline Formation (Eq. (1)) & $\mathrm{x}$ & $\mathrm{x}$ & $\mathrm{x}$ \\
\hline $\mathrm{C}_{2} \mathrm{H}_{2}$ growth (Eq. (3)) & $\mathrm{x}$ & $\mathrm{x}$ & $\mathrm{x}$ \\
\hline PAH growth (Eq. (6)) & $\mathrm{x}$ & $\mathrm{x}$ & $\mathrm{x}$ \\
\hline Oxidation (Eq. (8)) & $\mathrm{x}$ & $\begin{array}{c}\text { depending on } \\
\text { the PAH mass }\end{array}$ & $\begin{array}{c}\text { depending on } \\
\text { the PAH mass }\end{array}$ \\
\hline Soot nucleation (Eq. (12)) & $\begin{array}{c}\text { depending on } \\
\text { the PAH mass }\end{array}$ & \begin{tabular}{c} 
PAH \\
\hline
\end{tabular}
\end{tabular}


Table 3: Constants used in the soot formation model. Units are mol, m, s, K.

\begin{tabular}{|c|c|c|c|c|c|c|c|}
\hline \multicolumn{8}{|c|}{ PAH constants } \\
\hline \multicolumn{2}{|c|}{$N_{p}=4$ or 8} & \multicolumn{2}{|c|}{$M_{\mathrm{min}}^{P A H}=.1 \frac{\mathrm{kg}}{\mathrm{mole}}$} & $M_{\max }^{P A H}=.9 \frac{\mathrm{kg}}{\text { mole }}$ & \multicolumn{3}{|c|}{$\Delta M=\frac{1}{10 N_{p}}\left(M_{\max }^{P A H}-M_{\min }^{P A H}\right)$} \\
\hline \multicolumn{2}{|c|}{ Formation } & \multicolumn{2}{|c|}{$\mathrm{C}_{2} \mathrm{H}_{2}$ addition } & PAH addition & \multicolumn{3}{|c|}{ Oxidation } \\
\hline$R M$ & $\mathrm{H}$ & \multirow{3}{*}{$\begin{array}{l}A_{p_{i}}^{a d d} \\
T_{p_{i}}^{a d d}\end{array}$} & \multirow{3}{*}{$\begin{array}{c}3.98 \mathrm{e} 7 \\
5100\end{array}$} & \multirow{3}{*}{$\gamma=0.3$} & \multirow{2}{*}{\multicolumn{2}{|c|}{$\mathrm{O}_{2}$}} & $\mathrm{OH}$ \\
\hline$A_{p}^{\text {for }}$ & $3.98 \mathrm{e} 7$ & & & & & $2 \mathrm{e} 6$ & $2.1 \mathrm{e} 7$ \\
\hline$T_{p}^{f o r}$ & 5100 & & & & $T_{a_{i}}^{p_{i}}$ & 3800 & 2300 \\
\hline \multicolumn{8}{|c|}{ Soot constants } \\
\hline \multicolumn{2}{|c|}{ Nucleation } & \multicolumn{2}{|c|}{$\mathrm{C}_{2} \mathrm{H}_{2}$ condensation } & PAH addition & \multicolumn{3}{|c|}{ Oxidation } \\
\hline \multirow{5}{*}{\multicolumn{2}{|c|}{$\gamma=0.3$}} & \multirow{5}{*}{$\begin{array}{l}A^{\text {con }} \\
T_{a}^{c o n}\end{array}$} & \multirow{5}{*}{$\begin{array}{c}350 \\
12100\end{array}$} & \multirow{5}{*}{$\gamma=0.3$} & \multicolumn{3}{|c|}{$\mathrm{O}_{2}$} \\
\hline & & & & & $A_{\text {soot }}^{\text {ox }}$ & 742 & 8.82 \\
\hline & & & & & $n^{o x}$ & 0.5 & 0.5 \\
\hline & & & & & $T_{\text {soot }}^{o x}$ & 19800 & 0 \\
\hline & & & & & $\gamma$ & 1 & .13 \\
\hline
\end{tabular}


Table 4: Boundary conditions for the methane/air flame of Smooke et al.

\begin{tabular}{|c|c|c|c|c|}
\hline & radius $(\mathrm{mm})$ & composition & temperature $(\mathrm{K})$ & $\operatorname{velocity}\left(\frac{\mathrm{m}}{\mathrm{s}}\right)$ \\
\hline fuel inlet & 5.56 & $\mathrm{CH}_{4}: 1.0$ & 420 & 0.0552 \\
\hline air inlet & 47.625 & $\begin{array}{l}\mathrm{O}_{2}: .23 \\
\mathrm{~N}_{2}: .77\end{array}$ & 420 & .1254 \\
\hline wall & - & zero gradient & 300 & 0 \\
\hline
\end{tabular}


Table 5: Boundary conditions for the ethylene/air flame of McEnally et al. [22].

\begin{tabular}{lccccc}
\hline & radius $(\mathrm{mm})$ & \multicolumn{2}{c}{ mass fraction } & temperature $(\mathrm{K})$ & velocity $\left(\frac{\mathrm{m}}{\mathrm{S}}\right)$ \\
\hline \multirow{2}{*}{ air inlet } & \multirow{2}{*}{27.5} & $\mathrm{O}_{2}:$ & 0.23 & 300 & .338 \\
& & $\mathrm{~N}_{2}:$ & 0.77 & & \\
fuel inlet & 6 & $\mathrm{C}_{2} \mathrm{H}_{4}:$ & 0.174 & & .189 \\
& & $\mathrm{O}_{2}:$ & 0.100 & 300 & 0 \\
wall & & $\mathrm{N}_{2}:$ & 0.726 & & 0 \\
\hline
\end{tabular}


Table 6: Boundary conditions for the simulation of the kerosene surrogate/air flame of Moss and Aksit [21].

\begin{tabular}{cccccc}
\hline & radius $(\mathrm{mm})$ & \multicolumn{2}{c}{ composition } & temperature $(\mathrm{K})$ & velocity $\left(\frac{\mathrm{m}}{\mathrm{s}}\right)$ \\
\hline \multirow{2}{*}{ air inlet } & - & $\mathrm{O}_{2}:$ & 0.23 & 366 & .5 \\
& & $\mathrm{~N}_{2}:$ & 0.77 & & \\
\multirow{3}{*}{ fuel inlet } & \multirow{5}{*}{5} & $\mathrm{C}_{10} \mathrm{H}_{22}:$ & 0.259 & & .22 \\
& $\mathrm{C}_{6} \mathrm{H}_{6}:$ & 0.042 & 540 & .2 \\
& $\mathrm{~N}_{2}:$ & 0.699 & & \\
\hline
\end{tabular}

